\title{
EVALUATION OF RESUSCITATION KNOWLEDGE AND SKILLS IN DENTISTS BEFORE AND AFTER A EUROPEAN RESUSCITATION COUNCIL CPR/AED COURSE
}

\begin{abstract} Introduction:

To investigate the level of knowledge of Greek dentists in cardiopulmonary resuscitation (CPR) and of the use of the Automated External Defibrillator (AED) before and after participating in a European Resuscitation Council (ERC) CPR/AED course.
\end{abstract}

\section{Materials and methods:}

A theoretical knowledge questionnaire consisting of multiple choice questions was completed by the participants at the beginning of the CPR/AED course. The participants were re-evaluated at the end of the course, while the evaluation procedure consisted of two distinct parts: a 10-min written test which preceded a simulated cardiac arrest scenario.

\section{Introduction}

Cardiac arrest is a major cause of death worldwide (1-3). In the United States (USA), the referring frequency of occurrence of out-of-hospital cardiac arrest (OHCA) in individuals aged between 50 and 79 is $1.9 / 1000$ per year (2). In Europe, the annual incidence of out-of-hospital cardiac arrest (OHCA) for all rhythms is 38 per 100,000 population, while the annual incidence of ventricular fibrillation (VF) arrest is 17 per 100,000 (3). On initial heart rhythm analysis, about $25-30 \%$ of OHCA victims have VF, but when the rhythm is recorded, soon after collapse, the incidence can be as high

\section{USTANOUA}

${ }^{1}$ National and Kapodistrian University of Athens, Medical School, Postgraduate Study Program (MSc) "Cardiopulmonary Resuscitation", Athens, Greece ${ }^{2}$ Hellenic Society of Cardiopulmonary Resuscitation, Athens, Greece

${ }^{3} 2^{\text {nd }}$ Department of Obstetrics and Gynecology, Neonatal Division, National and Kapodistrian University of Athens,

Medical School, Athens, Greece

${ }^{4}$ European University Cyprus, School of Medicine, Nicosia, Cyprus

\section{Results:}

The average performance of the participants in pre-course written test was satisfactory, while the dentists who had attended a CPR/AED course in the past achieved significantly higher initial performance in contrast to their colleagues $(p=0.028)$. There was a statistically significant increase in post-course test score compared to pre-course test score (8.3 \pm 1.2 vs. $5.7 \pm 1.9$, respectively; $p<0.001)$. In addition, participation in a CPR/AED course had a positive effect on the participant's skills, as their performance was excellent at the end of the course.

\section{Conclusions:}

Dentists' resuscitation knowledge and skills were significantly improved after participating in ERC CPR/AED courses. as $59-65 \%(4,5)$. For every minute that defibrillation is delayed, survival from witnessed VF decreases by $10-12 \%$, while survival to hospital discharge can be as high as $75 \%$, if defibrillation is performed within 3 min of collapse (6-8).

In a British study, cardiac arrest was extremely rare in dental practice with an incidence of 0.002 cases per dentist per year (9), while in Germany, it was estimated that one sudden cardiac arrest occurs per 638,960 patients in dental practice (10). Considering however that dentists today treat a growing number

\section{AUTOR ZA}

\section{KORESPODENCIJU:}

Dr. Athanasios Chalkias, National and Kapodistrian University of Athens, Medical School, Postgraduate Study Program (MSc) "Cardiopulmonary Resus citation", 3 Ir. Politechniou Av., 18532, Piraeus, Greece. Tel.: +302110121756; Fax: +302110121758, Email: thanoschalkias@yahoo.gr

\section{KLUČNE REČl:}

cardiopulmonary resuscitation;

automated external defibrillator; dentists
DATUM PRIJEMA RADA

10. oktobar 2015

DATUM PRIHUATANA RADA

20. oktobar 2015.

DATUM OBJaVLUVANIA

10. jun 2016. 
of elderly patients and patients suffering from serious illnesses, they may need to be competent in performing high quality cardiopulmonary resuscitation (CPR). The aim of our study was to investigate the level of knowledge of Greek dentists in cardiopulmonary resuscitation (CPR) and the use of the Automated External Defibrillator (AED) before and after participating in a European Resuscitation Council (ERC) CPR/ AED course.

\section{Methods}

The study was conducted in Athens, Greece, recruiting dentists who had applied on their own will for CPR/ AED training at the Hellenic Society of CPR. Participants were all individuals aged $>25$ years, while participation to the study was voluntary with participants giving informed consent.

\section{Questionnaire}

A questionnaire consisting of multiple choice questions was used in our study. This questionnaire has been described elsewhere and has been used previously (11). The questionnaire consisted of two parts, i.e. demographics and 10 multiple choice theoretical knowledge questions with only one correct answer that surveyed familiarity with the 2010 ERC CPR/ AED guidelines (Appendix). Each of the questions of the course test surveying theoretical knowledge was followed by four possible answers, one of which was correct. One point was allocated to any correct answer with no negative marking; therefore, the total maximum score was 10 . The test was scored in order to ensure a uniform theoretical knowledge among the participants of the study, while competency was arbitrarily set and was indicated when the candidate answered correctly at least eight questions (80\%).

\section{CPR/AED Course format}

During the study period, three ERC CPR/AED courses with dentists were organized as previously described (11). The ratio of instructor to candidates was 1:6, with at least one manikin and one AED for each group of six candidates (12). The manikin used was 'Little Anne' (Laerdal Medical Corporation, NY, USA). The AED used was the Zoll AED plus-Trainer with self-adhesive defibrillation pads. An AED connector that simulates different cardiac arrest rhythms was also used for training purposes.

The instructor group comprised of ERC-certified CPR/ AED instructors, while all dentists were instructed by the same group to ensure uniform training, as previously described (13). All instructors were certified providers, nominated by the course faculty as having instructor potential, who have successfully completed the CPR/AED instructor course and have achieved instructor status after being successfully monitored as instructor candidates for a minimum of two CPR/AED courses. The participants were formally evaluated at the end of the course, while the evaluation procedure consisted of two distinct parts: a 10-min written test (Appendix) which preceded a simulated cardiac arrest scenario.

\section{The testing scenario}

After a 2 min introduction by two instructors, the trainee took the role of the rescuer and had to recognize cardiac arrest and effectively provide CPR according to the CPR/AED algorithm. The scenario given to each participant was a patient, found unconscious, who required the use of an $A E D$ in a public place. The initial cardiac rhythm when the AED was attached was VF (13). The same scenario was used for each participant, who was then asked to perform the CPR/AED algorithm in real time (defibrillation-2 min CPR-defibrillation), until professional care arrived. The instructors used the usual skills testing sheet criteria to determine if the trainee has demonstrated each step of the skill correctly and to record the student's results. Each parameter in the checked list was considered to be completed successfully, only if both of the instructors agreed. An appropriate performance in this simulated scenario is required to get the "pass" grade. Any mistakes during the scenario testing led to "retest" grade and re-examination of the candidate. Repetition of these mistakes resulted in failure to complete the course.

\section{Statistical Analysis}

Data are expressed as mean \pm 1 standard deviation (S.D.) for continuous variables and as frequency (percentage \%) for categorical data. The normality of the distributions was assessed with Kolmogorov-Smirnov test and graphical methods. Comparisons of continuous variables were performed using Student's t-test and Mann-Whitney's $U$, non-parametric test, as appropriate. Categorical data were compared by the $\chi 2$-test, or Fisher's exact test, as required. Pearson's correlation coefficient and Spearman's rho were calculated in order to examine linear relationships between variables. All tests were two-sided. Differences were considered as statistically significant if the null hypothesis could be rejected with $>95 \%$ confidence $(p<0.05)$. 


\section{Results}

Of the 74 dentists who were initially invited, all (100\%) were recruited in our study. The demographic characteristics of the respondents are shown in Table 1. Of them, $48(65.8 \%)$ knew what an AED is, while 73 $(98.6 \%)$ declared that there is not an AED available in their work place. Moreover, $13(26.5 \%)$ had attended a CPR/AED course in the past but did not know what an AED is.

In our study, 48 (66.7\%) dentists stated that they have little confidence in providing CPR and delivering defibriIlation, $22(30.6 \%)$ that they have no confidence at all, and only $2(2.8 \%)$ of them are very confident in CPR and defibrillation delivery. The participants who were very confident in CPR achieved lower performance at the multiple choice compared to those who stated that they have little confidence $(p=0.026)$ and those that claimed that they have no confidence at all $(p=0.026)$.

Written test

The average performance of the participants in pre-course written test was poor $(5.7 \pm 1.9)$. Of note, $62(83.6 \%)$ failed to give a correct answer in question 3 and $54(73 \%)$ failed in question 5 . The dentists who had attended a CPR/AED course in the past achieved significantly higher initial performance in contrast to their colleagues $(p=0.028)$. In our study, there was a statistically significant increase in post-course test score compared to pre-course test score $(8.3 \pm 1.2 \mathrm{vs}$. $5.7 \pm 1.9$, respectively; $p<0.001$ ) (Table 2 ).

Practical evaluation

In cardiac arrest scenario, most dentists' performance was excellent and achieved a "pass" grade. Eleven $(14.9 \%)$ dentists who did not call for help and $7(9.4 \%)$ who did not provide effective chest compressions completed the course after successful re-examination (Table 3).

\section{Discussion}

Although cardiac arrest in the dental practice is rare, dentists should be competent in providing CPR and use the AED. Indeed, increasing evidence suggest that the ability of the dentist to initiate primary management is the key to minimizing morbidity and mortality $(9,14)$. The most important finding of our study, which is the first one conducted in Greece aiming at evaluating the knowledge of Greek dentists in CPR/AED, was

Table 1. Demographic characteristics of the participants [N $(\%)]$

\begin{tabular}{|c|c|c|}
\hline \multirow{2}{*}{ Sex } & Male & $39(52.7)$ \\
\hline & Female & $35(47.3)$ \\
\hline \multirow{2}{*}{ Age $(\bar{x} \pm$ SD) } & Male & $47.5 \pm 10.53$ \\
\hline & Female & $40.3 \pm 10.65$ \\
\hline \multirow{2}{*}{ Postgraduate Studies } & MSc & $13(17.6)$ \\
\hline & $\mathrm{PhD}$ & $2(2.7)$ \\
\hline \multirow{2}{*}{ Time since graduation $(\bar{x} \pm \mathrm{SD})$} & Male & $20.3 \pm 10.16$ \\
\hline & Female & $13.7 \pm 9.01$ \\
\hline \multirow{3}{*}{ Work Sector } & Public sector & $3(4.1)$ \\
\hline & Private employee & $1(1.4)$ \\
\hline & Freelance & $69(94.5)$ \\
\hline \multirow{2}{*}{ Training in CPR/AED in the past } & Yes & $49(66.2)$ \\
\hline & No & $25(33.8)$ \\
\hline \multirow{2}{*}{ Training in CPR/AED during undergraduate studies } & Yes & $34(46.6)$ \\
\hline & No & $39(53.4)$ \\
\hline \multirow{2}{*}{ Necessity of CPR/AED for the dentists } & Yes & 71 (95.9) \\
\hline & No & $3(4.1)$ \\
\hline \multirow{2}{*}{ Knowledge of AED } & Yes & $48(65.8)$ \\
\hline & No & $25(34.2)$ \\
\hline \multirow{2}{*}{ Existence of AED in the work place } & Yes & $1(1.4)$ \\
\hline & No & 73 (98.6) \\
\hline \multirow{2}{*}{ Previous participation in CPR } & Yes & $3(4)$ \\
\hline & No & $71(96)$ \\
\hline
\end{tabular}

$\mathrm{CPR}=$ cardiopulmonary resuscitation; $\mathrm{AED}=$ automated external defibrillator. 
Table 2. Number of correct answers in written test n (\%)

\begin{tabular}{|c|c|c|c|c|c|}
\hline Question & 1 & 2 & 3 & 4 & 5 \\
\hline Prior to the course & $40(54.1)$ & $52(70.3)$ & $12(16.4)$ & $57(77)$ & $20(27)$ \\
\hline At the end of the course & $57(79.2)$ & $68(94.4)$ & $53(73.6)$ & $72(100)$ & $70(97.2)$ \\
\hline Question & 6 & 7 & 8 & 9 & 10 \\
\hline Prior to the course & $52(70.3)$ & 68 (91.9) & $45(60.8)$ & $39(52.7)$ & $36(48.6)$ \\
\hline At the end of the course & $69(95.8)$ & $68(94.4)$ & $48(66.7)$ & $44(61.1)$ & $49(68.1)$ \\
\hline
\end{tabular}

that they lack the knowledge needed in order to be able to provide early high quality CPR and use the AED. According to the Resuscitation Council of the United Kingdom (UK), all dentists should undergo training in CPR and basic airway (15). Although specific legislation has been enacted in our country in 2007 regarding the compulsory training of all health care professionals in CPR/AED and most of our participants reported that it is necessary for the dentist to be certified in CPR/AED, only $46.6 \%$ of them were trained in CPR/AED in the past. However, health authorities must implement this legislation as soon as possible. In UK, dental students participate in a similar course at least once during their study period (16), while in USA, training in medical emergency is obligatory in 41 out of 43 Schools of Dentistry. Specifically, in $22(51 \%)$ of 43 Schools of Dentistry, education in medical emergencies is a distinct course, while in the remaining Schools it is incorporated in other courses (17).

In our study, most dentists stated that they have little confidence or that they do not have confidence at all in performing CPR which is consistent with literature $(10,18,19)$. This can be explained not only by the lack of training and awareness of current guidelines, but also, by the rapid deterioration of CPR/AED skills after the initial training. Various studies reported that about $88 \%$ of those who attend a CPR/AED course are not competent in providing effective CPR within a period of a year after the end of course (5,20-22).

Despite the fact that both the knowledge and skills of the participants improved after attending the CPR/ AED course the majority of dentists reported that there is no AED available in their work place. This could be attributed to the fact that the vast majority of them work at the own private practice and the cost of an AED acts as a deterrent. At the same time, there is no national legislation that obliges the dentists to acquire an AED as well. Knowing that prompt defibrillation saves lives, we believe that it is unacceptable for a dentist not to have an AED among his/her resuscitation equipment and specific legislation should be enacted and implemented as soon as possible towards to this purpose. In the same spirit, the Resuscitation Council of UK specifies that a dental office should include an AED in its basic equipment, while in USA only in some states the dental offices are obliged to include an AED in their equipment by law (23).

Table 3. Evaluation in practical skills

\begin{tabular}{ll} 
Skill & Successful performance N (\%) \\
\hline Looking for potential dangers & $70(94.5)$ \\
\hline Checking responsiveness & $71(96)$ \\
Calling for help & $63(85)$ \\
\hline Head tilt and chin lift & $70(94.5)$ \\
\hline Checking for normal breathing & $72(97.3)$ \\
\hline Activating the emergency medical services & $73(99)$ \\
\hline Performing high quality chest compressions & $67(90.5)$ \\
\hline Giving two effective rescue breaths & $69(93.2)$ \\
\hline Maintains a ratio of 30 compressions to 2 ventilations & $73(99)$ \\
\hline Switch on the AED & $71(96)$ \\
\hline Correctly attaches the pads & $72(97.3)$ \\
\hline Allows rhythm analysis whilst making sure that nobody touches the victim & $71(96)$ \\
\hline Demonstrates rapid and safe delivery of a shock & $72(97.3)$ \\
\hline Minimizes interruptions to chest compressions & $69(93.2)$
\end{tabular}




\section{Limitations}

One limitation of this study is the limited study size. In addition, the environment of a cardiac arrest scenario is controlled and use of the same questionnaire over time might have artificially increased overall CPR success; in a "real-life" cardiac arrest many factors could complicate the process of resuscitation and some lay rescuers might panic easily, with unpredicted outcomes on victims' survival rates $(5,12)$. Finally our study examined the short-term skill and knowledge retention of the participants and long-term deterioration is unknown.

\section{Conclusion}

Dentists' resuscitation knowledge and skills were significantly improved after participating in a ERC CPR/AED course. The implementation of the existing legislation regarding the compulsory training of all health care professionals in CPR/AED is mandatory.

\section{Conflict of interest: None \\ Acknowledgements: Nothing to acknowledge \\ References}

1. Go AS, Mozaffarian D, Roger VL, et al; American Heart Association Statistics Committee and Stroke Statistics Subcommittee. Heart disease and stroke statistics--2013 update: a report from the American Heart Association. Circulation 2013; 127: e6-245.

2. Rea TD, Pearce RM, Raghunathan $T E$, et al. Incidence of out-of-hospital cardiac arrest. Am J Cardiol 2004; 93: 1455-1460.

3. Atwood C, Eisenberg MS, Herlitz J, Rea TD. Incidence of EMS-treated out-of-hospital cardiac arrest in Europe. Resuscitation 2005; 67: 75-80.

4. Cobb LA, Fahrenbruch CE, Olsufka M, Copass MK. Changing incidence of out-of-hospital ventricular fibrillation, 1980-2000. JAMA 2002; 288: 3008-3013.

5. Nolan JP, Soar J, Zideman DA, et al. European Council Guidelines for Resuscitation 2010 Section 1, executive summary. Resuscitation 2010; 81: $1219-1276$.

6. Stiell IG, Wells $G A$, Field $B$, et al. Improved out-of-hospital cardiac arrest survival through the inexpensive optimization of an existing defibrillation program: OPALS study phase II, Ontario prehospital advanced life support. JAMA 1999; 281: 1175-1181.

7. Valenzuela TD, Roe DJ, Nichol G, Clark LL, Spaite
DW, Hardman RG. Outcomes of rapid defibrillation by security officers after cardiac arrest in casinos. N Engl J Med 2000; 343: 1206-1209.

8. Caffrey S. Feasibility of public access to defibrillation. Curr Opin Crit Care 2002; 8: 195-198.

9. Girdler NM, Smith DG. Prevalence of emergency events in British dental practice and emergency management skills of British dentists. Resuscitation 1999; 41: 159-167.

10. Müller MP, Hänsel M, Stehr SN, Weber S, Koch T. A state-wide survey of medical emergency management in dental practices: incidence of emergencies and training experience. Emerg Med J 2008; 25: 296-300.

11. Xanthos T, Ekmektzoglou KA, Bassiakou E, et al. Nurses are more efficient than doctors in teaching basic life support and automated external defibrillator in nurses. Nurse Educ Today 2009; 29: 224-231.

12. Soar J, Monsieurs KG, Balance JHW, et al. European Resuscitation Council Guidelines for Resuscitation 2010 Section 9. Principles of education in resuscitation. Resuscitation 2010; 81: 1434-1444.

13. Papalexopoulou K, Chalkias A, Dontas I, et al. Education and age affect skill acquisition and retention in lay rescuers after a European Resuscitation Council CPR/AED course. Heart Lung 2014; 43: 66-71.

14. Gonzaga HF, Buso L, Jorge MA, Gonzaga LH, Chaves MD, Almeida OP. Evaluation of knowledge and experience of dentists of São Paulo State, Brazil about cardiopulmonary resuscitation. Braz Dent J 2003; 14: 220-222.

15. The Resuscitation Council (UK). Medical emergencies and resuscitation. Standards for clinical practice and training for dental practitioners and dental care professionals in general dental practice. A Statement from The Resuscitation Council (UK). London, Resuscitation Council (UK), 2012. (Accessed 19 May 2013, at http://www.resus.org.uk/ pages/MEdental.pdf).

16. Graham CA, Scollon D. Cardiopulmonary resuscitation training for UK undergraduate dental students. Resuscitation 1996; 32: 105-108.

17. Clark MS, Wall BE, Tholström TC, Christensen EH, Payne BC. A twenty-year follow-up survey of medical emergency education in U.S. dental schools. J Dent Educ 2006; 70: 1316-1319.

18. Chapman PJ. A questionnaire survey of dentists regarding knowledge and perceived competence in resuscitation and occurrence of resuscitation emergencies. Austr Dent J 1995; 40: 98-103. 
19. Atherton GJ, McCaul JA, Williams SA. Medical emergencies in general dental practice in Great Britain. Part 3: perceptions of training and competence of GDPs in their management. Br Dent J 1999; 186: 234-237.

20. Zeitz CJ, Zeitz KM, Ward G, Inglis A. The acquisition and maintenance of defibrillation skills by lay first responders. Resuscitation 2003; 56: 77-82.

21. Laurent F, Augustin P, Nabet C, Ackers S, Zamaroczy D, Maman L. Managing a Cardiac Arrest: Evalu-

\section{Appendix}

1. Which of the following is a sign of cardiac arrest?
a. Severe chest pain.
b. Dyspnoea.
c. Choking.
d. Absence of breath.

2. According to the CPR/AED algorithm, responsiveness can be assessed by:
a. Calling 112.
b. Shaking the victim's shoulder and asking loudly:
"Are you okay?"
c. Getting an AED.
d. Performing two cycles of CPR and waiting for the victim's response.

3. In case of an unresponsive victim, the first action should be:
a. Do nothing until someone gets an AED.
b. Look, listen and feel for breathing.
c. Activate the EMS.
d. Shout for help.

4. When calling 112, what information should be available to the EMS center?
a. The rescuer's name.
b. The victims' status.
c. The location.
d. a, b and c.

5. According to the 2010 European Resuscitation Council guidelines on CPR/AED, what is the correct compression to ventilation ratio?
a. $30: 2$.
b. $5: 1$.
c. $15: 5$.
d. $10: 2$

ation of Final-Year Predoctoral Dental Students. J Dent Educ 2009; 73: 211-217.

22. Berden HJ, Willems FF, Hendrick JM, Pijls NH, Knape JT. How frequently should basic cardiopulmonary resuscitation training be repeated to maintain adequate skills? BMJ 1993; 306: 1576-1577.

23. Two more states require AEDs in dental offices. Wisconsin, Cardiac Science, 2012. (Accessed 30 May 2013, at http://www.cardiacscience.com/ blog/).

6. Rescue breaths can be characterized as adequate when:
a. Air blowing lasts for $2 \mathrm{sec}$.
b. Breathing sounds are heard. c. The victim's chest rises when blowing into the
mouth.
d. Head tilt/chin lift is not maintained during rescu- e breathing.

7. An AED can be life-saving in case of:
a. Heart attack.
b. Cardiac arrest.
c. Choking.
d. Seizures.

8. When there is a readily available AED, the rescuer(s) should:
a. Plug in the AED.
b. Turn on the AED.
c. Attach the pads on the victim's chest.
d. Continue chest compressions.

9. Touching the victim during shock delivery is not allowed because:
a. The AED analysis may be wrong.
b. The AED will not defibrillate the victim.
c. Lay persons may be shocked accidentally.
d. All of the above.

10. When breathing is absent, which of the following is the WORST thing you can do?
a. Performing CPR even though you cannot remem- ber the algorithm.
b. Using the AED even though you are not sure how to do it.
c. Waiting for the EMS personnel to arrive.
d. $a$ and $b$. 